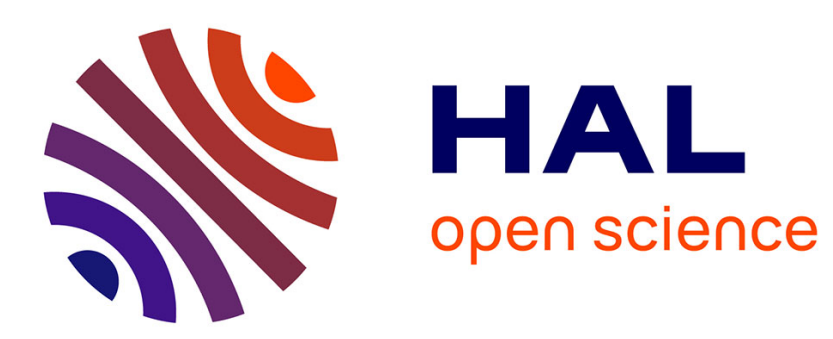

\title{
Collateral constraints and rental markets
}

Hippolyte d'Albis, Eleni Iliopulos

\section{- To cite this version:}

Hippolyte d'Albis, Eleni Iliopulos. Collateral constraints and rental markets. Economics Letters, 2013, 121, pp.436-439. 10.1016/j.econlet.2013.09.013 . hal-00964867

\section{HAL Id: hal-00964867 \\ https://hal.science/hal-00964867}

Submitted on 24 Mar 2014

HAL is a multi-disciplinary open access archive for the deposit and dissemination of scientific research documents, whether they are published or not. The documents may come from teaching and research institutions in France or abroad, or from public or private research centers.
L'archive ouverte pluridisciplinaire HAL, est destinée au dépôt et à la diffusion de documents scientifiques de niveau recherche, publiés ou non, émanant des établissements d'enseignement et de recherche français ou étrangers, des laboratoires publics ou privés. 


\title{
Collateral constraints and rental markets*
}

\author{
Hippolyte d'Albis \\ Paris School of Economics, University of Paris 1 \\ Eleni Iliopulos ${ }^{\dagger}$ \\ Paris School of Economics, University of Paris 1 and CEPREMAP
}

September 3, 2013

\begin{abstract}
We study a benchmark model with collateral constraints and heterogeneous discounting. Contrarily to a rich literature on borrowing limits, we allow for rental markets. By incorporating this missing market, we show that impatient agents choose to rent rather than to own the collateral in the neighborhood of the deterministic steady state. Consequently, impatient agents are not indebted and borrowing constraints play no role in local dynamics.

JEL classification: E30, R31.

Keywords: heterogeneous discounting, collateral constraints, rental market, credit market.
\end{abstract}

\section{Introduction}

In recent years, a rich literature has developed to study the role of collateral constraints in driving fluctuations throughout the business cycle.

Collateral constraints are a common feature of housing finance in the developed world (IMF, 2008; Iacoviello, 2010; Calza et al. forthcoming). They are aimed at responding to enforcement limits of debt contracts: in case of default, the creditor can seize borrowers' real assets. Moreover, the

${ }^{*}$ H. d'Albis acknowledges financial support from the European Research Council (ERC Stg Grant DU 283953).

${ }^{\dagger}$ Corresponding author: Eleni Iliopulos, Paris School of Economics, University of Paris 1 Panthéon-Sorbonne, Maison de Sciences Economiques, 106-112, Boulevard de l'Hôpital, 75647 PARIS Cedex 13. eleni.iliopulos@univ-paris1.fr 
structure of this type of debt limits implies a strong linkage between agent's access to credit and real estate markets, which is of empirical relevance.

Introducing borrowing limits into an otherwise frictionless framework entails significant deviations from the Modigliani-Miller theorem. Moreover, all shocks affecting the value of the collateral are amplified and spread throughout the economy via their impact on credit markets themselves. However, for this financial accelerator mechanism to work, two ingredients are necessary. First, the borrowing limit has to bind in equilibrium. Second, at each period the economy needs to be populated by a set of agents willing both to lend and borrow up to the limit. Becker (1980) and Becker and Foias (1987) show that one way to insure this is to introduce discount-factors heterogeneity. Indeed, impatient agents are always debt constrained while patient agents are willing to lend.

Kiyotaki and Moore (1997) introduce collateral constraints on land value together with heterogeneous discount rates to study the impact of the financial accelerator mechanism. They show how the propagation mechanism mentioned above can be decomposed into a static multiplier and a powerful dynamic multiplier entailing persistent cycles.

Following Kiyotaki and Moore (1997), a large literature has developed incorporating heterogeneous discounting to insure binding collateral constraints. Iacoviello (2005) introduces collateral constraints into the housing market. Because the structure of credit limits implies that agents can borrow more whenever their housing wealth rises, there is a strong correlation between movements in housing wealth and movements in aggregate consumption. Indeed, relatively poor people with lower propensity to save respond more to changes in housing wealth. These properties of the model allow him to explain the amplification of cycles and to match some empirical stylized facts (Iacoviello 2010).

In light of the extensive use of the benchmark model in the literature, we analyze some fundamental features of the model and their implications for the equilibrium. To this purpose, we focus on a standard housing model where the collateral is real estate ${ }^{1}$. We believe that the standard framework is based on the implicit assumption that the only way to benefit from housing services is to own real properties. We relax this assumption by introducing a rental market. Thus the modified model accounts for agents who can own real assets and produce housing services for themselves, and renters who buy housing services from landlords. Agents face a portfolio decision; they confront the trade-off between investing in real estate or in financial

\footnotetext{
${ }^{1}$ Alternatively, we could have chosen as collateral land or other durable collaterizable assets. This would not have changed the results of our analysis.
} 
assets / being indebted. Our analysis shows that in this context, in contrast to the above mentioned literature, the optimal behavior of the impatient agent generically consists in not investing in housing. Therefore, the equilibrium is characterized by no private debt. Indeed, the impatient agent aims at increasing current consumption as much as possible. When agents can borrow less than the entire value of their house (i.e., the loan-to-value ratio is less than one), any increase in real properties implies a less than proportional increase in private borrowing, and thus, current consumption. In this case, impatient agents choose not to invest in housing thereby consuming all of period-t income. Consequently, the credit market collapses and impatient agents buy housing services on the rental market, leaving no role to collateral constraints.

\section{The model}

There are two types of agents who are characterized by different discount rates. Both agents derive utility from consuming nondurable goods and housing services. They can buy and/or rent housing units (i.e., square meters) and have access to the credit market. Henceforth, we will denote the agent having a relatively higher preference for the present as the impatient agent, and the one with the highest discount rate, as the patient one.

The objective function of the representative impatient agent at date $t=0$ can be written as:

$$
\max _{c_{t}, h_{t}} E_{0} \sum_{t=0}^{\infty} \beta^{t} u\left(c_{t}, h_{t}\right),
$$

where $c_{t}$ represents nondurable consumption, $h_{t}$ represents consumption of housing services, $\beta \in(0,1)$ is the discount factor and function $u(.,$.$) is$ increasing, concave and satisfies the Inada conditions in both arguments. Finally, $E_{0}$ is the expectation operator conditional to the information set at date $t=0$. The budget constraint at date $t \geq 0$ can be written as:

$$
p_{t} s_{t}-d_{t}+c_{t}+p_{t} l_{t}\left(h_{t}-s_{t}\right)=p_{t} s_{t-1}-R_{t-1} d_{t-1}+y_{t},
$$

where $p_{t}$ is the relative price of one unit of housing $s_{t}$, and $d_{t}$ is outstanding private debt. Moreover, $l_{t}$ is the rent-to-price ratio, $R_{t}$ is the interest factor that prevails on the credit market and $y_{t}$ is the (exogenous) income endowment. Therefore, $p_{t} s_{t}-d_{t}$ represents the net wealth of the agent and $p_{t} l_{t}\left(h_{t}-s_{t}\right)$ represents the rent paid to or received from the landlord depending on whether the agent eventually buys (i.e., rents housing) or produces (i.e., owns and rents) housing services. 
An impatient agent's debt, $d_{t}$, is constrained to be less than or equal to a share $m \in(0,1)$ of the expected present value of their housing holdings. Following Kiyotaki and Moore (1997), the constraint can be written as:

$$
d_{t} \leq m s_{t} \frac{E_{t} p_{t+1}}{R_{t}}
$$

The housing stock cannot be negative, thus:

$$
s_{t} \geq 0 \text {. }
$$

Let us denote by $u_{1}^{\prime}\left(c_{t}, h_{t}\right) \varphi_{t}$ the Kuhn-Tucker multiplier associated with the collateral constraint (3) and by $u_{1}^{\prime}\left(c_{t}, h_{t}\right) \zeta_{t}$ the one associated with the non-negativity constraint (4). The first order conditions of the impatient agent with respect to housing assets and debt read as:

$$
\begin{aligned}
-p_{t}\left(1-l_{t}\right)+\beta \frac{E_{t} p_{t+1} u_{1}^{\prime}\left(c_{t+1}, h_{t+1}\right)}{u_{1}^{\prime}\left(c_{t}, h_{t}\right)}+m \varphi_{t} \frac{E_{t} p_{t+1}}{R_{t}}+\zeta_{t} & =0, \\
1-R_{t} \beta \frac{E_{t} u_{1}^{\prime}\left(c_{t+1}, h_{t+1}\right)}{u_{1}^{\prime}\left(c_{t}, h_{t}\right)}-\varphi_{t} & =0 .
\end{aligned}
$$

Condition (5) represents the arbitrage between the marginal cost of investing in housing, $p_{t}\left(1-l_{t}\right)$, and the marginal gain deriving from future nondurable consumption and from increasing borrowing, provided that constraint (3) is binding. When (3) is not binding, $\varphi_{t}$ is equal to zero and condition (6) is the standard Euler equation with respect to private debt. When $\varphi_{t} \neq 0$, the marginal utility of present consumption is larger than the discounted utility of future consumption. Therefore, agents borrow up to the limit to increase current consumption and constraint (3) is binding. Moreover, complementary slackness conditions can be written as:

$$
\begin{aligned}
\left(m s_{t} \frac{E_{t} p_{t+1}}{R_{t}}-d_{t}\right) \varphi_{t} & =0, \\
s_{t} \zeta_{t} & =0 .
\end{aligned}
$$

The representative patient agent is similar to the impatient one. The main difference lies in the discount factor, $\mu \in(\beta, 1)$. The objective function of the patient agent at date $t=0$ can be written as:

$$
\max _{c_{t}^{*}, h_{t}^{*}} E_{0} \sum_{t=0}^{\infty} \mu^{t} u\left(c_{t}^{*}, h_{t}^{*}\right),
$$

where starred letters refer to patient-agent variables. The budget constraint is the same as the one described in (2) except that $b_{t}^{*}$ are bonds (i.e., the funds lent to impatient agents):

$$
p_{t} s_{t}^{*}+b_{t}^{*}+c_{t}^{*}+p_{t} l_{t}\left(h_{t}^{*}-s_{t}^{*}\right)=p_{t} s_{t-1}^{*}+R_{t-1} b_{t-1}^{*}+y_{t}^{*} .
$$


For simplicity, we do not introduce borrowing constraints as, in equilibrium, the patient agent holds a non-negative quantity of bonds, provided that the relative transversality condition is imposed. Moreover, the patient agent's housing stock cannot be negative:

$$
s_{t}^{*} \geq 0
$$

Let us denote by $u_{1}^{\prime}\left(c_{t}^{*}, h_{t}^{*}\right) \kappa_{t}$ the Kuhn-Tucker multiplier associated with the non negativity constraint (11). The intertemporal arbitrage conditions with respect to $s_{t}^{*}$ and $b_{t}^{*}$ can be written as:

$$
\begin{aligned}
-p_{t}\left(1-l_{t}\right)+\mu \frac{E_{t} p_{t+1} u_{1}^{\prime}\left(c_{t+1}^{*}, h_{t+1}^{*}\right)}{u_{1}^{\prime}\left(c_{t}^{*}, h_{t}^{*}\right)}+\kappa_{t} & =0, \\
-1+R_{t} \mu \frac{E_{t} u_{1}^{\prime}\left(c_{t+1}^{*}, h_{t+1}^{*}\right)}{u_{1}^{\prime}\left(c_{t}^{*}, h_{t}^{*}\right)} & =0 .
\end{aligned}
$$

They represent the patient-agent counterpart of conditions (5) and (6). Moreover, the complementary slackness condition is:

$$
s_{t}^{*} \kappa_{t}=0
$$

\section{Equilibrium}

In equilibrium, market clearing conditions for nondurable goods $\left(c_{t}+c_{t}^{*}=\right.$ $\left.y_{t}+y_{t}^{*}\right)$, housing services $\left(h_{t}+h_{t}^{*}=s_{t}+s_{t}^{*}\right)$ and for the credit market $\left(d_{t}=b_{t}^{*}\right)$ need to hold.

We now focus on a deterministic steady state characterized by constant levels for all variables, including relative prices. Our main result is the following.

Proposition. Impatient agents hold no debt or housing assets and buy housing services from patient agents on the rental market.

Proof. At the steady state, condition (13) determines the interest factor, $R=1 / \mu$, which, once replaced in condition (6), gives $\varphi=1-\beta / \mu>0$. Moreover, condition (12) gives the rent-to-price ratio: $l=1-\mu-\kappa / p$. Substituting the resulting values for $R, \varphi$ and $l$ into condition (5) gives: $\zeta=p(1-m)(\mu-\beta)+\kappa$. This condition allows us to conclude that $\zeta>0$. This and (8) imply that $s=0$ and, using condition (7), that $d=0$. The market clearing condition on the credit market implies $b^{*}=0$, while the one on the housing market implies $s_{t}^{*}>0$. Finally, (11) implies $\kappa>0$. 
The above Proposition represents the main point of this note and deserves some discussion.

At the steady state where marginal utilities are constant, one of the two types of agents needs to be constrained because of the unique interest rate. If the interest rate was determined by the discount rate of the impatient agent, the patient agent would be willing to lend his entire endowment. Because of the Inada conditions on consumption, this cannot be an equilibrium of our model. On the contrary, if the interest rate depended on the discount rate of the patient agent, the impatient agent would be willing to borrow as much as possible to increase his current-period consumption, but would be constrained by the borrowing limit. This is a possible equilibrium. Therefore, $R=1 / \mu$. This result has been emphasized by Becker (1980) and Becker and Foias (1987) in a framework with an infinite number of discount factors and a non-negativity constraint on capital. Indeed, in the presence of discountfactor heterogeneity, the interest rate is eventually set by the "dominant consumer": the most patient agent and the only one who accumulates capital. No other agents accumulate capital as they use their current incomes for consumption.

However, according to the above considerations, it would be surprising if the impatient agent invested in housing units, as any increase in real properties raises his net asset position and decreases current consumption. Indeed, debt is strictly lower than the discounted value of housing. Thus, the impatient agent does not invest in housing, implying via the collateral constraint, a zero net asset position. The impatient agent is constrained; however, allowing for the rental market implies that he does not accumulate housing units. Thus, he does not have access to borrowing and the credit market eventually plays no role.

Moreover, given that the marginal utility of housing services tends to infinity when the housing stock tends to zero, the patient agent wants to own real properties. As expected, the no-arbitrage condition between debt and real assets entails equating their returns. At the steady state where all variables and prices are constant, the return on housing only depends on the opportunity cost of renting (i.e., the rent to price ratio, $l$ ). The return on real assets is in turn equal to: $1 /(1-l)$. The rent-to-price ratio is thus equal to $l=1-\mu$ and the dominant consumer imposes both the interest rate and rents.

There are only two cases where it is optimal for the impatient agent to invest in housing. The first case is the one considered by the aforementioned literature. When real assets are incorporated into the utility function and/or 
into the production function ${ }^{2}$, housing investment is necessary because of Inada conditions. There is not a clear-cut consensus about the economic appropriateness of incorporating assets into the utility function. Convincing examples supporting this modelling decision are Carroll (2000) and the literature related to the "spirit of capitalism" (Zou, 1995). However, the assumption is used to explain the right tail of the wealth distribution ${ }^{3}$. This is clearly at odds with the above mentioned literature, where the entire population eventually needs to own real estate. Also, while being meaningful for housing services, the Inada conditions cannot be imposed on housing assets. Note finally that having housing into the utility function can be interpreted as imperfect altruism, which is at odd with an infinitely lived rational agent. Bequest considerations would thus not affect our analysis unless we introduce overlapping generations and change the entire structure of the model (Iacoviello and Pavan, 2013).

Alternatively, there is a second and limit case, when $m=1$. In the above analysis, we have excluded the possibility for the loan-to-value ratio to be equal to one both on theoretical and empirical fundamentals. Indeed, $m<1$ is consistent both with debt contracts to be subject to enforcement limits (Kiyotaki and Moore, 1997) and with empirical evidence (Calza et al., forthcoming). In this context, the portfolio of the impatient agent is indeterminate. Investing in real assets entails an equivalent increase in debt, which does not eventually modify his net asset position or affect his consumption. The following corollary focuses on this point.

Corollary. Let $m=1$, then $s \geq 0$ and $s^{*} \geq 0$ with at least one inequality holding strictly. Moreover, $s$ and $s^{*}$ are indeterminate.

Proof. When $m=1, \zeta=p(1-m)(\mu-\beta)+\kappa=\kappa$. Therefore, $\zeta=$ $\kappa>0$, implying $s=0, d=0$ and $s^{*}=0$. However, the Inada conditions on housing services imply that at least one of the two agents needs to hold housing assets, excluding this possibility. Alternatively, if $\zeta=\kappa=0$ and thus $s \geq 0$ and $s^{*} \geq 0$, with at least one of the two inequalities holding strictly. Finally, by substituting the steady-state values $R=1 / \mu, \varphi=1-\beta / \mu$ and $l=1-\mu$ together with the steady-state arbitrage condition between housing and nondurable consumption, $u_{2}^{\prime}(c, h)=u_{1}^{\prime}(c, h) p l$, into (2), it is straightforward to see that the impatient agent's nondurable consumption is only affected by current income, $y$, for any level of housing holdings, $s$.

\footnotetext{
${ }^{2}$ Instead of introducing housing into the utility function, we could have instead introduced it into the production function, as in Kiyotaki and Moore (1997). Our results would still hold.

${ }^{3}$ However, with uninsurable idiosyncratic risk, Luo and Young (2009) show that spirit of capitalism preferences lead to less inequality in wealth.
} 
Analogous considerations apply for the patient agent.

\section{References}

[1] Becker, Robert, A. 1980. "On the Long-Run Steady State in a Simple Dynamic Model of Equilibrium with Heterogeneous Households." Quarterly Journal of Economics 95: 375-382.

[2] Becker, Robert A. and Ciprian Foias. 1987. "A Characterization of Ramsey Equilibrium." Journal of Economic Theory 41: 173-184.

[3] Calza, Alessandro, Tommaso Monacelli and Livio Stracca. "Housing Finance and Monetary Policy." Journal of the European Economic Association. Forthcoming.

[4] Carrol, Christopher, D. 2000. "Why Do the Rich Save So Much?" in Slemrod, J. B. (Ed.), Does Atlas Shrug? The Economic Consequences of Taxing the Rich. Harvard University Press.

[5] Iacoviello, Matteo. 2005. "House Prices, Borrowing Constraints and Monetary Policy in the Business Cycle." American Economic Review 95 (3): 739-764.

[6] Iacoviello, Matteo. 2010. "Housing in DSGE Models: Findings and New Directions." in Bandt, O. de; Knetsch, Th.; Peñalosa, J.; Zollino, F. (Eds.), Housing Markets in Europe: A Macroeconomic Perspective, Berlin, Hidelberg: Springer-Verlag.

[7] Iacoviello, Matteo. 2011. "Housing Wealth and Consumption." International Encyclopedia of Housing and Home. Elsevier.

[8] Iacoviello, Matteo, and Marina Pavan. 2013. "Housing and Debt over the Life Cycle and over the Business Cycle." Journal of Monetary Economics, 60 (2): 221-238

[9] International Monetary Fund. 2008. "The Changing Housing Cycle and the Implications for Monetary Policy." World Economic Outlook: 1-30.

[10] Kiyotaki, Nobuhiro and John Moore. 1997. "Credit Cycles." Journal of Political Economy 105: 211-48. 
[11] Luo, Yulei and Eric R. Young. 2009. "The Wealth Distribution and the Demand for Status." Macroeconomic Dynamics, 13 (S1):1-30.

[12] Zou, Heng-Fu. 1995. "The Spirit of Capitalism and Long-Run Growth." European Journal of Political Economy 10 (2): 279-293. 